\title{
Por um outro princípio da realidade: o sentido formativo da estética em H. Marcuse
}

In another principle of reality: the sense in formation aesthetic $\mathrm{H}$. Marcuse

Vivian Baroni*

Universidade de Passo Fundo

Resumo Tendo por base a filosofia de Herbert Marcuse, o presente artigo objetiva demonstrar a possibilidade de superação do princípio da realidade por meio dos pressupostos fornecidos pela educação estética. Centrada na formação do sujeito como um todo, a educação estética de Marcuse aproxima-se do conceito de Bildung, focando-se na tarefa de trazer de volta à racionalidade moderna as dimensões humanísticas que foram bloqueadas pelo processo da racionalização instrumental. Ao rechaçar a lógica competitiva e dar ênfase à libertação instintual, a educação estética seria capaz ainda de fomentar uma nova estrutura da experiência, que modificaria de modo essencial a relação dos indivíduos com os objetos e com o meio. Desse modo, a educação estética poderia projetar uma tecnologia livre para a realização do seu telos original: a preservação da vida.

PALAVRAS-CHAVE: Marcuse; Princípio da realidade; Educação estética.

Abstract Based on the philosophy of Herbert Marcuse, this paper aims to demonstrate the possibility of overcoming the principle of reality through the assumptions provided by the aesthetic education. Centred in the formation of the subject as a whole, the aesthetic education of Marcuse approaches the concept of Bildung, focusing on the task of bringing back to modern rationality humanistic dimensions that were blocked by the instrumental rationalization process. To fend off the competitive logic and emphasize instinctual release, aesthetic education could still foster a new structure of experience that would change the essential way the relationship of individuals with the objects and the environment. Thus, the aesthetic education could design a free technology for the realization of its original telos: the preservation of life.

KEYWORDS: Marcuse; The reality principle; Aesthetic education. 


\section{Introdução}

Diante de um panorama em que o aparato tecnológico é instrumentalizado para servir como veículo de conformismo, no qual o avanço científico já não expressa o necessário avanço humanístico, cabe questionar os fundamentos éticos e morais que dirigem o progresso nas sociedades avançadas. $\mathrm{E}$ na medida em que a dinâmica mais ampla da sociedade se reflete nos processos educativos, o resultado passa a ser a reificação e mercantilização da dimensão formativa, o que é demonstrado no âmbito científico pelo crescente interesse das pesquisas educacionais pelo empírico, entendido como um dado que fala por si mesmo.

Portanto, é necessário ressaltar a importância do estudo dos clássicos como obras que ultrapassam a sua condição histórica e percorrem o tempo mantendo seu sentido inalterado para assim nos influenciar novamente, ou seja, "um clássico é um livro que nunca terminou de dizer aquilo que tinha para dizer" (CALVINO, 1993, p. 11). No âmbito educacional, o estudo sistemático de autores e obras clássicas estimula a fundamentação sólida da pesquisa educativa em parâmetros teóricos, firmando a construção de um saber consistente, que no diálogo com a tradição, fomenta um debate crítico com os problemas contemporâneos.

Logo, a teoria de Marcuse, ao ser reapropriada e trabalhada em outras dimensões e em consonância com as mudanças históricas, pode promover o debate contemporâneo sobre a dominação e emancipação nas sociedades avançadas. Nesse sentido, o presente ensaio tem por objetivo estudar a possibilidade de superação do princípio da realidade por meio dos pressupostos fornecidos pela educação estética. Concentrando-se na abordagem da obra de Marcuse, procuramos demonstrar como a educação estética marcuseana converge para uma ideia de formação que se aproxima do conceito de Bildung. No compromisso com o direcionamento da técnica para a pacificação da existência, a educação estética incita um processo formativo do sujeito como um todo: uma autoformação que se refere ao desenvolvimento da consciência crítica, sensibilidade estética e julgamento moral.

\section{O princípio da realidade em Freud e Marcuse}

Para Freud, o indivíduo é eternamente infeliz porque tem que se sujeitar às exigências do princípio da realidade, submetendo a natureza à vontade humana para que, enquanto comunidade humana e com o auxílio da técnica oriunda da ciência, possa prover as condições básicas que lhe permitam gozar de uma vida sem percalços. Sob o predomínio do princípio da realidade, "aquilo que chamamos 'felicidade', no sentido mais estrito, vem da satisfação repentina de necessidades altamente represadas, e por sua natureza é possível apenas como fenômeno episódico"(FREUD, 2010/1930, p. 21). Freud (2010/1930, p. 29) indica como fatores determinantes da infelicidade humana sob o princípio da realidade três causas principais: a prepotência da natureza, a fragilidade do nosso corpo e a insuficiência das normas que regulam os vínculos humanos na família, no Estado e na sociedade.

No entanto, para Marcuse (1975, p. 51), o argumento da preponderância do princípio da realidade freudiano pode ser considerado falacioso na medida em que se aplica ao fato concreto da carência, quando, na verdade, é apenas a consequência 
de uma organização específica da carência e de uma igualmente específica atitude imposta por essa organização. Ora, é sabido que com a modernidade o progresso técnico e científico possui a possibilidade de eliminar drasticamente o trabalho desgastante e repressivo, aumentando o acesso à informação e ao tempo livre, o que permite uma maior flexibilização das metas instintuais. A historicização da teoria requer, contudo, uma duplicação dos conceitos, na qual os termos freudianos de repressão e princípio da realidade devem ser emparelhados com os seus correspondentes histórico-sociais específicos: mais-repressão, as restrições requeridas pela dominação social, e princípio do desempenho, a forma histórico-contemporânea assumida pelo princípio da realidade.

O princípio do desempenho se apresenta como a ideia amplamente difundida de que a vida é uma irrestrita competição para atingir o primeiro lugar, ter o melhor desempenho. No entanto, o desempenho máximo nunca pode ser alcançado pelo indivíduo em virtude da mais-repressão, controles adicionais acima e além dos indispensáveis à satisfação básica das necessidades e à formação da sociedade. O princípio do desempenho é característico de uma sociedade aquisitiva e antagônica em processo de constante expansão, pressupondo um longo desenvolvimento durante o qual a dominação foi crescentemente racionalizada (MARCUSE, 1975, p. 58). Nesse processo, parte da energia libidinal de Eros é desviada e utilizada no trabalho socialmente necessário, impondo uma modificação na própria substância do princípio do prazer, isso porque a adesão ao princípio do desempenho "implica a subjugação da força destrutiva da gratificação instintiva, de sua incompatibilidade com as normas e valores estabelecidos e, por conseguinte, implica a transubstanciação do princípio do prazer" (MARCUSE, 1975, p. 35).

Contudo, o progresso científico e tecnológico alcançado pela civilização ocidental, sob a égide do princípio do desempenho, parece ter fornecido as pré-condições para o estabelecimento de um princípio da realidade não-repressivo. Essa premissa funda-se basicamente em duas tendências históricas: 1) o nível da produtividade alcançado pelo progresso da civilização permite que as exigências instintivas consumidas em trabalho alienado possam ser consideravelmente reduzidas; 2) embora a filosofia representativa da civilização ocidental tenha desenvolvido um conceito de razão que contém as características dominantes do princípio do desempenho, essa mesma filosofia aponta para uma forma superior de razão que é a própria negação dessas características (MARCUSE, 1975, p.123-124).

Marcuse (1975, p. 125) afirma que a luta pela existência implica uma modificação repressiva dos instintos, principalmente quando isso se refere à falta de meios e recursos para sua gratificação integral. Desse modo, a organização repressiva dos instintos se daria mediante fatores exógenos no sentido de não serem inerentes à própria natureza dos instintos, mas oriundos das condições históricas específicas nas quais se desenvolveram. Logo, é possível afirmar a possibilidade histórica da libertação essencial do princípio do prazer por meio dos pressupostos fomentados pelo princípio do desempenho, quais sejam, o amplo desenvolvimento tecnológico e a possibilidade de redução do tempo de trabalho. O fato da mais-repressão se basear em uma organização específica da escassez, sendo que a escassez como fato concreto é superável pelo 
princípio do desempenho, define o ponto de ruptura que permite a Marcuse explorar a possível ruína da organização repressiva dos instintos que mantém o indivíduo atrelado à exploração.

A libertação instintual resulta, em última instância, no desenvolvimento livre da libido e, consequentemente, no retorno de Eros às bases da razão moderna. Sob a égide do princípio do desempenho, a gratificação do instinto sexual exige a supressão da consciência. Em contraste, para além do princípio do desempenho, a gratificação do instinto requer um esforço consciente de livre racionalidade: "com a transformação da sexualidade em Eros, os instintos de vida desenvolvem sua ordem sensual, ao passo que a razão se torna sensual na medida em que abrange e organiza a necessidade em termos de proteção e enriquecimento dos instintos de vida" (MARCUSE, 1975, p. 194). Assim, a essência da experiência estética reemerge não apenas na cultura artística, mas na própria existência, ou seja, assume uma nova racionalidade.

\section{Tecnologia e razão: a superação do princípio da realidade na nova sensibilidade}

No entanto, a tecnologia que define a forma e a direção do progresso no princípio do desempenho encontra-se restringida pela sua concepção quantificadora e instrumentalista, visto que a ciência se desenvolveu sob o a priori tecnológico que projeta a natureza como material de controle e organização. $\mathrm{E}$ a apreensão da natureza como instrumento precede o desenvolvimento de toda a organização técnica particular (MARCUSE, 1978, p. 150). Para Marcuse, a quantificação da natureza, que levou o projeto científico a explicá-la em termos de estruturas matemáticas, separou a realidade de todos os fins inerentes: o verdadeiro do bem, a ciência da ética, enfim, a técnica de seu telos original. Logo, independente do quão constitutivo possa ser a função do objeto como ponto de medição e cálculo, esse objeto jamais pode desempenhar seu papel científico como agente ético, estético ou político (MARCUSE, 1978, p. 144).

A extensão do projeto científico às variáveis sociais, assim como o fato de que as relações humanas assumem cada vez mais a forma da objetividade dos sistemas conceituais das ciências quantitativas, reforçam a afirmativa marcuseana da confluência, no nível da experiência, entre ciência, tecnologia e sociedade. Na razão científica, as coisas da experiência são divididas em componentes mensuráveis e as relações entre esses componentes explicados casualmente como parte de um maquinário natural. Para Marcuse, essa nova concepção de razão é a ciência a priori, a pré-condição de ver e experimentar o mundo (FEENBERG, 2012, p. 144). Embora no âmbito da pesquisa científica o instrumentalismo não seja essencialmente deletério, ele se modifica quando as possibilidades de controle instrumental disponibilizadas pela ciência a priori são exploradas em larga escala pela tecnologia.

A unidade entre ciência e tecnologia estabelece-se no fato de que a realidade quantificável da ciência é uma realidade instrumentalizável para a sociedade. A conexão entre ciência, tecnologia e sociedade é a forma a priori da experiência por elas compartilhada (FEENBERG, 2012, p. 144). O fato é que a ciência, em virtude de seu próprio método e de seus conceitos, acabou por projetar um universo no qual a 
dominação da natureza permaneceu ligada à dominação do homem, fundindo a hierarquia racional com a hierarquia social. No entanto, se essa ligação mantém o aparato da dominação técnica atuante no mundo social, é na mudança da direção do progresso que reside a possibilidade do rompimento com essa ligação fatal, que também passa a afetar a própria estrutura da ciência. Para Marcuse (1978, p. 160), as hipóteses do projeto científico, sem perder o seu caráter racional, passam a se desenvolver em um contexto experimental essencialmente diferente: o de um mundo apaziguado. "Consequentemente, a ciência chegaria a conceitos de natureza essencialmente diferente e estabeleceria fatos essencialmente diferentes. A sociedade racional subverte a ideia de razão" (MARCUSE, 1978, p. 160).

O que Marcuse quer dizer é que se a racionalidade científica está ligada à dominação, existe ao mesmo tempo a possibilidade de que ela seja reapropriada pelas práticas emancipatórias mediante a emergência de uma nova experiência que restauraria o seu propósito original: a preservação da vida. De acordo com Feenberg (2012, p. 143), com base no movimento da Nova Esquerda, Marcuse pôde imaginar uma nova estrutura de experiência, na qual uma orientação rumo à potencialidade libertaria o potencial crítico da reflexão. Ou seja, a relação da técnica com a realidade contém um potencial inerente de dominação em virtude da ligação entre sociedade e ciência, primordialmente metodológica e neutra em relação aos valores circundantes na sociedade. No entanto, a sua própria neutralidade cancela essa consideração devido às potencialidades dos homens e das coisas, passíveis de alcançar o seu telos na medida em que sejam livres para isso.

Assim, Marcuse contrasta um a priori repressivo, aquele característico do princípio do desempenho, voltado exclusivamente para a dominação, com um a priori alternativo, que cumprisse o telos da técnica. $\mathrm{Na}$ busca desse telos, o a priori alternativo criaria uma sociedade harmônica, junção de Eros e Logos. A alternativa libertária seria baseada em um modo de experiência diferente do vigente, desenvolvida no ensaio A nova sensibilidade (MARCUSE, 1969). A nova sensibilidade refere-se, sobretudo, à projeção de um ideal de vida estético, orientado para a pacificação da existência em vez de para a dominação. É um modo diferente de estruturação da experiência, na qual os instintos de vida encontrariam expressão racional no planejamento e distribuição do tempo de trabalho social, assim como entre os vários ramos da produção, determinando as prioridades dos objetivos e seleções: não somente o que se deve produzir, mas também a forma do produto (MARCUSE, 1969, p. 30).

O importante é reconhecer que a nova sensibilidade opera em um nível mais elementar que o da política, se dando no plano das experiências pessoais em si mesmas: ela deve se incorporar ao cotidiano sob a forma de percepção. Para Marcuse, a tecnologia amplia sua abrangência para além dos limites traçados pelo equipamento, o que implica modos de pensar e práticas que envolvem uma restruturação da realidade como objeto de controle. Logo, tornar-se liberto desse modo de experiência só é possível por meio de outra forma de experiência, da transformação de práticas essenciais que se justificam na nova sensibilidade. Como ressalta Feenberg (2010a, p. 318), a referência de Marcuse à estética constituinte da nova sensibilidade pode ser entendida não como a introdução do critério de beleza no interior do julgamento político, mas 
como forma a priori de um novo tipo de experiência pertencente a uma nova ordem social. Nesse sentido, Marcuse evoca o âmbito sensível como contraponto à racionalidade iluminista, apontando para a necessidade de incorporação da sensibilidade nos critérios de julgamento do real: "a verdade da arte não é a verdade do pensamento conceitual, da filosofia ou da ciência, a qual configura a realidade. O elemento da arte é a sensibilidade interna e externa, o estético; ela é antes receptiva do que positiva" (MARCUSE, 2001b, p. 48).

A ideia da libertação instintual defendida por Marcuse se depara com o argumento de que uma maior flexibilização instintual pode causar o fim da civilização, que somente poderia se manter pela renúncia e o trabalho. Contra isso, Marcuse procura demonstrar a possibilidade de ascensão de uma civilização não-repressiva no amadurecimento da própria civilização. A direção de tal desenvolvimento é marcada por aqueles elementos e forças mentais que, de acordo com Freud, conservaram-se livres do princípio da realidade: a fantasia e a imaginação. Como âmbitos da criação artística e representantes do antagonismo em relação ao princípio da realidade, invocam o poder da dimensão estética na transformação da realidade:

$$
\begin{aligned}
& \text { as verdades da imaginação são vislumbradas pela primeira vez } \\
& \text { quando a própria fantania ganha forma, quando cria um universo de } \\
& \text { percepção e compreensão - subjetivo e, ao mesmo tempo, objetivo. } \\
& \text { Isso ocorre na arte. A análise da função cognitiva da fantasia nos } \\
& \text { conduz assim à estética como "ciência da beleza": subentendida na } \\
& \text { forma estética situa-se a harmonia reprimida do sensualismo e da } \\
& \text { razão - o eterno protesto contra a organização da vida pela lógica } \\
& \text { da dominação, a crítica do princípio do desempenho (MARCUSE, } \\
& \text { 1975, p. 135). }
\end{aligned}
$$

O elemento erótico na imaginação visa uma realidade em que os instintos vitais se realizem numa gratificação sem repressão. A total oposição ao princípio da realidade permite à imaginação desempenhar um papel único na dinâmica mental. Em virtude dessas características, Marcuse propõe dois arquétipos da imaginação como imagens da existência libertada. Ao contrário dos heróis da produtividade repressiva (Prometeu), a figura de Narciso e Orfeu "simbolizam a realização plena do homem e da natureza, não através da dominação e da exploração, mas pela liberação das inerentes forças libidinais" (MARCUSE, 1975, p. 158). É precisamente no conteúdo representativo das imagens órficas e narcísicas que é possível reestabelecer uma união erótica do homem e da natureza na atitude estética, na qual a ordem é beleza e o trabalho é impulso lúdico.

Para Feenberg (2010a, p. 318) a recuperação de um conceito transformador de razão que incorpore a imaginação é possível agora que a luta pela existência está essencialmente superada pelo avanço tecnológico, o que abre uma importante perspectiva para o futuro. Baseando-se em Kant, Marcuse (1975, p. 157) afirma que a imaginação intermedeia as sensações e a razão, elevando a experiência sensorial à universalidade da beleza. Logo, considerando a possibilidade de abolição da mais-repressão nas sociedades avançadas, a imaginação pode mudar seu lugar na sociedade: transbordando o âmbito da arte, a imaginação se coloca na centralidade da tarefa de reconciliar as demandas dos sentidos e da razão, organizando o conteúdo heterogêneo 
da experiência estética para gestar uma nova sensibilidade. Assim, a sociedade libertada pode guiar a prática produtiva emparelhada com a imaginação criativa da arte: "na medida em que os valores estéticos são os valores não-agressivos por excelência, a arte como tecnologia e como técnica também viria a implicar a emergência de novos modos e novos mitos do próprio progresso técnico" (MARCUSE, 1982, p. 251).

Embora a libertação instintual sob a base estética seja um pré-requisito para se pensar um outro princípio da realidade, o que Marcuse propõe não é um retorno à alienação cultural; exige, ao contrário disso, uma união entre a estética e a política, a qual vai encontrar na obra A educação estética do homem numa série de cartas, de Schiller (2002), as bases para a transposição da estética para a cultura. O ponto central para Marcuse situa-se no conceito de instinto lúdico, o impulso capaz de unificar o impulso formal e o sensual, tendo por objetivo a beleza e por finalidade a liberdade (MARCUSE, 1975 , p. 166). Stederoth (2003, p. 343) ressalta que essa unificação estética entre sensualidade e razão no lúdico, no "jogo", oferece para Marcuse o fundamento para uma reviravolta radical das perspectivas emancipatórias. Essa expectativa pode transformar o relacionamento de dominação entre o homem e a natureza, pois o que vale para a natureza exterior vale também para a natureza interna do homem: "para o conflito entre razão e sensibilidade, que devem ser esteticamente mantidos no relacionamento com a natureza externa relativo ao seu antagonismo tornado histórico, para uma nova forma de sensibilidade sensata, assim como para uma sensatez sensual" (STEDEROTH, 2003, p. 343).

A concepção da realidade social como bela ou horrenda é uma comparação comum usada por Marcuse, e em toda a sua obra ele descreve instâncias contemporâneas nas quais ilustra sua tese de que a estética é uma categoria fundamental da própria experiência social. De acordo com Feenberg (2010a, p. 303), em Marcuse as categorias e elementos da estética conduzem para um engajamento concreto das possibilidades políticas e técnicas que poderão se realizar nas configurações alternativas da realidade social. Nesse sentido, a experiência estética situa-se precisamente na capacidade de reconstrução da tecnologia moderna para o acolhimento de um modo de vida que ultrapasse a luta pela existência: "a estética pode converter-se em uma teleologia historicizada, um conceito de essência em construção, mobilizadora de uma nova tecnologia para aplicações concretas" (FEENBERG, 2010a, p. 304).

Marcuse defende uma posição ambiciosa argumentando que poderia haver formas de racionalidade instrumental diferentes daquelas produzidas pela sociedade de classe; dessa forma, um novo tipo de razão instrumental ${ }^{1}$ poderia gerar uma nova ciência e novos projetos tecnológicos não-repressivos. Ou seja, em termos heideggerianos, Marcuse propõe uma nova abertura do ser por meio da transformação das práticas básicas (FEENBERG, 2010b, p. 257). Isso conduziria a uma mudança na própria natureza da instrumentalidade, que seria modificada pelas metas instintuais libertadas. Nesse sentido, a prática estética oferece um modelo de instrumentalidade transformada, radicalmente diferente da conquista repressiva da natureza. Ainda que esse projeto pareça implausível, suas diretivas mais intuitivas aparecem nas realizações de determinados campos da atividade humana, como o movimento ecológico. Um exemplo é o contraste existente na arquitetura que não respeita a inclusão no ambiente, como manifestação de uma forma incontida, e outra que se harmoniza com a natureza, procurando integrar o humano ao natural de maneira sensível. 


\section{Educação estética e superação do princípio da realidade}

Embora a filosofia de Marcuse tenha sido essencialmente conceitual, a projeção da teorização na realidade social sempre foi uma preocupação do filósofo. Se por um lado a teoria determina o geral no particular e faz remontar seu conceito às manifestações imediatas e concretas da sociedade, por outro lado, ela deve se constituir no conjunto com a base empírica: as tendências e condições da transformação devem ser demonstráveis na sociedade dada (MARCUSE, 1983, p. 28). Nesse sentido, a educação estética de Marcuse nos fornece os elementos para um diálogo com os problemas educacionais contemporâneos sob a perspectiva de uma fundamentação teórica sólida, que não se restringe a uma simples teorização, mas se propõe a refletir seus pressupostos na objetividade.

Para Marcuse (apud KELLNER; LEWIS; PIERCE, 2008, p. 21) a educação estética refere-se, sobretudo, a quatro pontos essenciais: 1) negar a sociedade estabelecida; 2) antecipar tendências da sociedade futura; 3) criticar as tendências destrutivas e alienantes; 4) sugerir imagens de criatividade e inalienável unidade. Como repetitivamente ressaltou Marcuse, o belo estético é a grande recusa à unidimensionalidade e ao cômodo mundo capitalista, o que inclui necessariamente, a negação da educação nos moldes da perícia técnica e estandardização. Ao contrário disso, a educação estética exige uma formação que se firme na busca por resolver os problemas sociais comuns, como a degradação ambiental, os desastres humanos e ambientais causados pela ciência e a tecnologia, a pobreza e a miséria resultantes da expansão econômica e a destruição da vida causada pela tecnologia militar.

Como um modelo formativo que pauta-se essencialmente na crítica e negação das condições existenciais repressivas, a educação estética converge para uma rejeição da falsa neutralidade que apoia a objetividade. É justamente sobre essa falsa neutralidade que se mantém os valores da sociedade unidimensional e o objetivismo científico da técnica. No entanto, essa crítica não deve se bastar a si mesma: a educação estética exige, através da projeção de imagens de liberdade, a transformação da realidade. O belo e a dimensão estética possuem a radical, senão revolucionária, função de favorecer o desenvolvimento de necessidades vitais e sensuais, e inspirar ações que transcendam a condição presente. Aqui, a ênfase na estética projeta um panorama formativo sensível: na mediação com Eros, a razão adquire um caráter sensível que transcende o âmbito subjetivo, e na transformação do real, se move desde a dimensão cognitiva e sensual, em direção ao desenvolvimento ético, moral e político.

É no fomento a um modelo formativo que se pauta no desenvolvimento de aptidões multidimensionais, ética, estética, racional e crítica, que a educação estética de Marcuse fornece uma expressão vigorosa de Bildung. Como formação ampla, a educação em Marcuse tem o sentido de trazer de volta as dimensões humanísticas que foram bloqueadas pelo processo da racionalização instrumental. Trata-se, sobretudo, de utilizar as bases da racionalidade estética para pensar uma formação que transcenda a lógica predominante do princípio do desempenho e as realizações da sociedade unidimensional, e direcionar a ação radical na direção da justiça e realização humana. Cabe aqui a abertura de uma perspectiva de desenvolvimento que exige o elemento 
estético, a sensibilidade que a razão por si só não é capaz de produzir. De acordo com Hermann (2005, p. 75) "nesse sentido, o gosto não é fundamento da moral, mas a educação do gosto pode promover a aceitação do bem e a rejeição do mal”.

Em contraposição à desvalorização das forças imateriais pelo marxismo ortodoxo, para Marcuse a subjetividade é um importante pré-requisito da revolução: "a necessidade de mudança radical deve se basear na subjetividade dos próprios indivíduos, na sua inteligência e nas suas paixões, nos seus impulsos e nos seus objetivos" (MARCUSE, 1977, p. 17). A preocupação de Marcuse com os âmbitos subjetivos e individuais, a libertação dos instintos e da consciência dos próprios indivíduos, recai sobre um conceito de autoformação estética que equipara-se com a Bildung como cultivo de si: formação do homem como artífice de si mesmo.

Segundo Goergen (2009, p. 45), Bildung é "autoconstrução do ser humano e da constituição de sua vontade no permanente conflito entre a sensibilidade e a razão, ou seja, entre o indivíduo e a sociedade". $\mathrm{Na}$ tentativa de encontrar o equilíbrio entre o universal e o individual, o público e o privado, a educação estética não se restringe a uma formação subjetivista: um dos parâmetros essenciais é o cultivo de si, a autoformação do indivíduo para a interação transformadora com a realidade. As necessidades e faculdades libertárias, emancipatórias, não podem se desenvolver em um meio configurado por e para os impulsos agressivos, nem como o mero efeito de um novo conjunto de instituições sociais: podem emergir somente na prática coletiva de criação de um meio ambiente, nível por nível, passo a passo, na produção material e intelectual (MARCUSE, 1969, p. 38).

Logo, a educação estética como Bildung, referindo-se à formação ampla do indivíduo que se reflete na prática política, nos permite inferir a sua potencialidade na transformação do princípio da realidade estabelecido. Como formação que se caracteriza pela combinação da razão e intuição, como desenvolvimento harmônico das potencialidades dos sujeitos, retoma a importância da inclusão dos aspectos sensíveis e eróticos nos processos formativos da contemporaneidade, para assim, exigir uma racionalidade essencialmente humanística. De tal modo, engloba a ideia de uma razão sensível como necessidade primordial para se pensar o desenvolvimento econômico e social, influenciando a gestão das metas do próprio progresso técnico.

\section{Considerações finais}

Em Marcuse, a probabilidade de surgimento de um outro princípio da realidade, contrariamente à teoria freudiana, ressalta a necessidade de pensar as possibilidades emancipatórias que estão contidas no próprio projeto histórico. Ao questionar a imutabilidade da repressão instintual, Marcuse afirma a obrigatoriedade de se ativar necessidades orgânicas, biológicas, que estariam reprimidas ou suspensas pelo princípio do desempenho. Dessa maneira, as exigências emancipatórias alcançam um nível muito mais elementar, essencial: o próprio instinto.

Esse novo sentido emancipatório permite novos olhares e questionamentos no âmbito da formação, o que aponta para a importância representada pela educação estética marcuseana enquanto Bildung. A educação estética permite o conhecimen- 
to daquilo que é excluído pelo domínio conceitual e racionalizado, transcendendo as fronteiras unilateralmente racionais do projeto educacional iluminista. Como uma formação que somente se completa na dinâmica da sociedade, a diretriz da educação estética se firma em fortalecer nos sujeitos a capacidade de partilhar e gestar estratégias comuns no intuito de melhorar as condições da sociedade como um todo.

Ao desfazer a ideologia competitiva do princípio do desempenho e libertar os sentidos, a educação estética é também o substrato essencial de uma nova estrutura da experiência, que modifica de modo definitivo a relação dos indivíduos com os objetos e com o meio. Assim, torna-se capaz de projetar uma tecnologia liberta para a realização derradeira de seu telos original: a preservação da vida. A rejeição da produtividade tributária, característica da experiência estética, pode representar um estágio superior de desenvolvimento humano baseado nas realizações da própria sociedade tecnológica. Portanto, a configuração do meio pode ser impulsionada por uma educação estética em ação: práxis transformadora.

\section{Referências}

CALVINO, I. Por que ler os clássicos. Trad. Nilson Moulin. São Paulo: Companhia das Letras, 1993.

FREUD, S. O mal estar na civilização (1930). In: Obras completas vol. 18: O mal estar na civilização, novas conferências introdutórias e outros textos (1930-1936). Trad. Paulo Cezar de Souza. São Paulo, Companhia das Letras: 2010, p. 9-89.

FEENBERG, A. A tecnologia pode incorporar valores? A resposta de Marcuse para a questão da época. In: NEDER, R. T. (org.). A teoria crítica de Andrew Feenberg: racionalização democrática, poder e ideologia. Brasília: Observatório do Movimento pela Tecnologia Social na América Latina / CDS / UnB / Capes, 2010a, p. 289-336.

. Marcuse ou Habermas: duas críticas da tecnologia. In: NEDER, R. T. (org.). A teoria crítica de Andrew Feenberg: racionalização democrática, poder e ideologia. Brasília: Observatório do Movimento pela Tecnologia Social na América Latina / CDS / UnB / Capes, 2010b, p. 253-288.

. Fenomenologia de Marcuse: lendo o capítulo seis de O homem unidimensional. In: Congresso Internacional Fantasia e Crítica, 1, 2012, Belo horizonte. Caderno de textos, Belo Horizonte, ABRE, 2012, p. 140-152.

GOERGEN, P. Formação ontem e hoje. In: CENCI, A. V.; DALBOSCO, C. A.; MÜHL, E. H. (orgs.). Sobre filosofia e educação: racionalidade, diversidade e formação pedagógica. Passo Fundo: Editora Universidade de Passo Fundo, 2009, p. 25-63.

HERMANN, N. Ética e estética: a relação quase esquecida. Porto Alegre: EDIPUCRS, 2005.

KELLNER, D.; LEWIS, T. E.; PIERCE, C. On Marcuse: critique, liberation, and reschooling in the radical pedagogy of Herbert Marcuse. Sense Publishers: Rotterdam, 2008.

MARCUSE, H. Un ensayo sobre la liberación. Trad. de Juan García Ponce. México: Cuadernos de Joaquín Mortiz, 1969.

Eros e civilização: uma interpretação filosófica do pensamento de Freud. Trad. Álvaro Cabral. Rio de Janeiro: Zahar, 1975.

. A dimensão estética. Trad. de Maria Elisabete Costa. Lisboa: Edições 70, 1977.

A ideologia da sociedade industrial: o homem unidimensional. Trad. Giasone Rebuá. $6^{a}$ ed. Rio de Janeiro: Zahar, 1978. 
. A arte na sociedade unidimensional. In: LIMA, L. C. (org.). Teoria da cultura de massa. São Paulo: Paz e Terra, 1982.

. Teoría y praxis. In:

. Calas en nuestro tiempo. Barcelona: Icaria, 1983, p. 27-53.

SCHILLER, F. A educação estética do homem numa série de cartas. Trad. Roberto Schwarz e Márcio Suzuki. São Paulo: Iluminuras, 2002.

STEDEROTH, D. Educação a partir da unidimensionalidade: contribuição de H. Marcuse para uma teoria educacional crítica. In: DALBOSCO, C. A.; FLICKINGER, Hans-Georg (orgs). Educação e maioridade: dimensões da racionalidade pedagógica. São Paulo: Cortez; Passo Fundo: Editora UPF, 2003, p. 328-347.

\section{Notas}

${ }^{1} \mathrm{O}$ termo "instrumental" em Marcuse não tem uma conotação unicamente negativa, como utilizado por Adorno e Horkheimer. Aqui, ele se refere a um tipo de ação voltada para aplicações práticas, como um agir da técnica sobre o objeto e a natureza, de modo essencialmente não-repressiva.

* Doutoranda em Educação pela Universidade de Passo Fundo, Passo Fundo, Rio Grande do Sul. Brasil.

\section{Correspondência}

Vivian Baroni - Rua Julio Longui, n 345, Bairro São José. CEP: 99052-300, Passo Fundo, Rio Grande do Sul, Brasil.

E-mail: vivianbaroni@hotmail.com

Recebido em 24 de julho de 2015

Aprovado em 15 de dezembro de 2016 
